\title{
Esophageal Foreign Body in a Neonate: An Unusual Age of Presentation
}

\author{
Singh $\mathrm{H}^{1}$, Dhingra $\mathrm{B}^{2}$, Yadav $\mathrm{D}^{3}$, Aggarwal $\mathrm{V}^{4}$ \\ ${ }^{1}$ Dr. Harpal Singh, MBBS, Senior Resident (Paediatrics), ${ }^{2}$ Dr. Bhavna Dhingra, MBBS, MD, Assistant Professor, ${ }^{3}$ Dr. Dinesh \\ Yadav, MBBS, Senior Resident (Paediatrics), ${ }^{4}$ Dr. Varun Aggarwal, MBBS, Senior Resident (Paediatrics). All from the \\ Department of Paediatrics, Lady Hardinge Medical College, New Delhi, India.
}

Address for correspondence: Dr. Harpal Singh, E-mail:drharpal_06@rediffmail.com

\begin{abstract}
Ingestion of foreign bodies in neonates is very rare and can be life threatening. We describe a 20 days old neonate presented with vomiting, drooling of saliva and poor feeding tolerance. Chest radiograph showed a metallic foreign body in superior mediastinum. Foreign body was removed by rigid oesophagoscopy. The case describes the unusual age of presentation of foreign body and options available to remove these foreign bodies in neonates.
\end{abstract}

Key words: Esophagus, Foreign body, Neonate

\section{Introduction}

ngestion of foreign body (FB) is a common but serious problem in paediatric population. Most common age of presentation is between 6 months to 3 years ${ }^{1}$. Tendency of oral exploration of things is the primary underlying cause of this problem. Esophageal ingestion of foreign body in neonates is very unusual and rare occurrence $2,3,4,5$. In this article we describe a metallic (disc-battery) foreign body ingestion in a 20 days old neonate. Uncommon age of presentation and options available to remove these esophageal foreign bodies merits discussion.

\section{The Case}

A 20 days old female neonate from lower socioeconomic strata presented to our hospital with the complaints of vomiting, cough, drooling of saliva and poor feeding of 10 days duration. As per available history this was probably inserted by elder sibling while playing. On examination baby had mild tachypnoea but no stridor. There were conducted sounds on auscultation in both lung fields. Cardiovascular, abdominal and central nervous system examination did not reveal anything significant. Chest radiograph showed a radio opaque FB in the superior mediastinum (Figure 1). Lateral view $X$ ray (Figure 2) demonstrated the FB in upper oesophagus. Impacted FB (metallic disc battery) in upper oesophagus was successfully removed under general anesthesia by oesophagoscopy. After removal of the FB, there was

localized edema and minimal ulceration in upper part of oesophagus. A nasogestric tube was inserted after removal of foreign body and feeding was started after 24 hours.

\section{Discussion}

Foreign body ingestion is common and serious problem in pediatric population. Coins are the most common foreign body ingested by children. Most of the foreign bodies (80\%-90\%) do not requires any intervention. Twenty to thirty percent of foreign bodies are removed by endoscopic approach but less than $1 \%$ requires surgical intervention ${ }^{6}$.

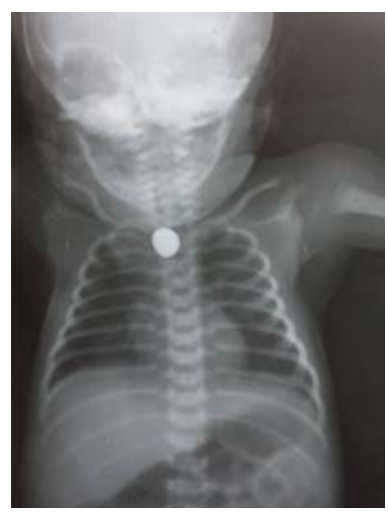

Fig 1: Chest radiograph showing radio-opaque $F B$ in superior mediastinum

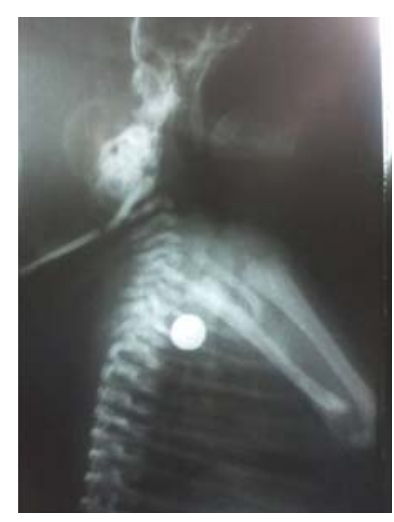

Fig 2: Lateral view radiograph showing $F B$ in upper esophagus 
Ingestion of foreign bodies is very uncommon in neonates. Various foreign bodies like stone ${ }^{3,5}$, ornament ring $^{4}$, button ${ }^{7}$ and safety pin $^{8}$ have been described in literature. Etiology behind these foreign bodies may be negligence or homicidal attempt for unwanted child. Common sites of impaction of foreign body are cricopharyngeal area, at the level of aortic arch and lower end of esophagus. These oesophageal foreign bodies not only present with typical manifestations like dysphagia, drooling of saliva, vomiting but also with respiratory manifestation including cough, respiratory distress, and stridor. These respiratory manifestations may be because of physical compression or erosion of trachea. Various other complications including erosion of aorta leading to life threatening hemorrhage, oesophageal perforation and abscess formation have been described ${ }^{6,9}$.

History and radiographic examination are very important in diagnosing $\mathrm{FB}$ ingestion in neonates. Endoscopy is a recommended method if the FB is radiolucent $^{10}$. Radiolucent foreign bodies can be visualized by computed tomography imaging, ultrasonography or magnetic resonance imaging ${ }^{11}$.

Endoscopic removal is the preferred method for oesophageal FB in neonates ${ }^{12}$. These can be removed by using Mc gill's forceps under direct laryngeoscopy ${ }^{13}$. Esophageal FB has been removed by using optical forceps in rigid bronchoscope ${ }^{4}$. Failure of removal of impacted FB by these approaches can be managed by cervical exploration ${ }^{5}$.

Parents and caretakers need to be counseled regarding taking adequate precautions with siblings of newborns as these problems can have dangerous and serious consequences.

\section{References}

1. Dahshan A. Management of ingested foreign bodies in children. J Okla State Med Assoc 2001;94:183-6

2. Banerjee A, Rao BK. Lower esophageal foreign body in a neonate (letter). Indian Pediatr 1983;20:384.
3. Thapa B R, Kaur B, Nagi B, et al. Unusual foreign body (stone) in the esophagus of a neonate mimicking tracheoesophageal fistula. Indian Pediatr 1993;30:943-5.

4. Tasneem Z, Khan MA, Uddin N. Esophageal foreign body in neonates. J Pak Med Assoc 2004;54:159-61.

5. Zameer M, Kanojia R, Thapa B R, Rao K. Foreign body oesophagus in a neonate: A common occurrence at an uncommon age. Afr J Paediatr Surg 2010;7:114-6.

6. Wahbeh G, Wyllie R, Kay M. Foreign body ingestion in infants and children: Location, location, location. Clin Pediatr (Phila) 2002;41:633-40.

7. Chowdhury CR, Bricknell MCM, Maclver D. Oesophageal foreign body: an unusual cause of respiratory symptoms in a three-week-old baby. J. Laryngol Otol 1992; 106:556-7.

8. Medatwal A, Gupta PP, Gulati RK. Multiple Foreign Bodies in a Neonate. Indian Pediatr 2008; 45:928-30.

9. Yalnin S, Karnak I, Ciftci AO, Senocak ME, Tanyel FC, Bóyókpamuknu N. Foreign body ingestion in children: An analysis of pediatric surgical practice. Pediatr S Urg Int 2007; 23:755-61.

10. Opasanon S, Akaraviputh T, Methasate A, Sirikun $J$, Laohapensang M. Endoscopic management of foreign body in the upper gastrointestinal tract: A tertiary care center experience. J Med Assoc Thai 2009; 92:17-21.

11. Young CA, Menias CO, Bhalla S, Prasad SR. CT features of esophageal emergencies. Radiographics 2008; 28:1541-53.

12. Wong KK, Fang CX, Tam PK. Selective upper endoscopy for foreign body ingestion in children: An evaluation of management protocol after 282 cases. J Pediatr Surg 2006;41:2016-8

13. Karaman A, Cavuwonlu YH, Karaman I, Erdonan D, Aslan MK, Cakmak O. Magill forceps technique for removal of safety pins in upper esophagus: A preliminary report. Int J Pediatr Otorhinolaryngol 2004; 68:1189-91.

\section{How to cite this article?}

Singh H, Dhingra B, Yadav D, Aggarwal V. Esophageal Foreign Body in a Neonate: An Unusual Age of Presentation. J Nepal Paediatr Soc 2012;32(1):79-80. 